\title{
UNA ADORACION DE PASTORES EN CHILPANCINGO
}

\author{
(TEATRO TRADICIONAL)
}

P O R

$$
V_{\mathbf{I}} \mathbf{E} \mathbf{N} \mathbf{T}: \mathrm{T} . \quad \mathrm{M} \text { E } \mathbf{N} \text { D O Z A }
$$

- DURante la breve permanencia que tuvimos, la profesora Virginia $R$. $R$. de Mendoza y el que suscribe, en la ciudad de Chilpancingo, con motivo de la Segunda Mesa Redonda de estudíos de la Ix Sesión del Congreso Mexicano de Historia, durante los días del 8 al 18 de enero del presente año, tuvimos noticias de que en el templo parroquial de Santa $\mathrm{Ma}$ ría de la Asunción inmediato al Palacio del Gobierno, había habido cánticos de pastores la noche del martes 11 . En la mañana del siguiente día, en compañía de nuestró compañero y amigo el profesor Celedonio Serrano Martínez, nos dimos a la tarea de conseguir informes sobre la posibilidad de escuchar dichos cantos, y obtuvimos del sacristán, señor Mariano Luna, la promesa de que por la noche se repetiría la actuación pastoril.

A eso de las ocho de la noche, al concluirse las labores del Congreso, acompañados del señor licenciado Gabriel Ferrer Mendiolea -quien pensaba encontrar en estos cantos la comprobación de la cita que hace Altamirano en su novela: "La Navidad en las Montañas", sobre villancicos 
de Navidad--, y algunas compañeras de trabajo, acudimos al templo y presenciamos lo que deseábamos, desde la llegada de los pastores y la iniciación de los cantos hasta la retirada del grupo.

Cómo fué la adoración.

Quince fueron los chiquillos que tomaron parte: seis niñas y nueve niños. Todos iban vestidos predominantemente de blanco; las niñas con vestido de linón, zapatos y medias blancas, sombrero dé cartón forrado de blanco y adornado con flores de papel; los varoncitos con chaqueta o blusa, pantalón corto, medias, zapatos y sombrero parecido a los de las niñas ; todos llevaban báculo forrado de papel blanco $\mathrm{y}$ adornado con cascabeles, charolitas de metal, flores y cintas de papel salpicadas de brillantina plateada. El ángel, vestido también de blanco, llevaba además espada, alas y corona. Uño de los más pequeños portaba también, una reata de lechugilla terciada, un guaje, una bocina de cuerno y una guitarrilla: era Sancho, el mayoral, jefe de los pastores, quien adernás, y a su tiempo, hizo el papel de Bartolo.

Uno de los muchachos más desarrollados, -tendria quince años-, era el ermitaño, llevaba un hábito improvisado, de lienzo oscuro, y con capucha, y el rostro cubierto de algodón para fingir la barba, que propiamente era una máscara, pues sólo se le veían los ojos a través de pequeñas aberturas.

El grupo estaba estacionado cerca de la entrada, formado en dos hileras, por parejas de hombre y mujer; en el centro, en la parte de atrás, el ermitaño; en medio el mayoral, $y$ al frente, el ángel; se destacó en primer lugar éste, avanzando hasta el altar y subiendo al presbiterio declamó con voz aguda y gran rapidez las estrofas iniciales y cantó el Gloria in Excelsis. Luego todo el grupo, sin avanzar, entonó el primer canto: "A Belén acudamos..." Lentamente se adelantaron y cantaron: "El infierno tiembla..." e iniciaron la marcha con la caminata: "Vamos pastorcitos...", deteniéndose a la mitad del templo en donde entonaron: "Esta es la Señora..." Iniciaron la adoración por parejas y avanzando hasta el altar cantaron: "Qué apacible luz..."; subian al presbiterio, hacian su ofrenda y bajaban al pie del mismo en donde sucesivamente iban diciendo la copla: "Qué gracia y qué gloria...", y mientras retrocedian a su lugar de origen, el coro entonaba: "Vamos, pastores, vamos a ver ..." Esto se repitió, exactamente, en la adoración de las 
seis parejas, así como en la del mayoral y del ermitaño, sólo que Sancho avanzó tocando su guitarra.

Cuando le llegó su turno a Bartolo (el mismo niño que fungió de Sancho), dejando su báculo y guitarra, se tendió en el suelo y rodeado de los demás pastores dió lugar al gracioso diálogo cantado hasta que el ángel vino a levantarlo. Sin moverse de su sitio el grupo, y sin cambiar la formación, ejecutaron los pastorcitos los demás cánticos, casi siempre con voces agudas y movimientos rápidos. Asi fueron entonados: "Aromas se quemen ..."; el arrullo "Cuando el Niño llora ...", "Cierra, cierra esos ojitos...", la canción "Pajarillo..." y la despedida "Ya nos retiramos...", y diciendo $y$ haciendo se fueron acercando a la salida del templo en donde se disolvió el grupo.

\section{Cómo se obtuvo el manuscrito.}

El jueves 13, por la mañana, nos trasladamos al domicilio de la señorita Fernanda González, que es la persona que se ha dado al trabajo de alentar esta clase de representaciones religiosas, y al informarle de nuestro propósito, con la mayor gentileza y buena voluntad nos mostró el manuscrito en que se halla consignado el texto íntegro de esta adoración. Desde luego nos dijo que es muy antiguo, que ella lo aprendió en su niñez de-labios de su madre la señora Fílomena, esposa de Juan González, quien a su vez lo recibió de la señora Epifanía Castor, abuela de la comunicante. Por lo tanto, si nuestra informante que tiene cincuenta años de edad, lo aprendió de su madre a principios de este siglo, y ésta a su vez lo recibió de la suya siendo niña, es seguto que esta adoración ya se cantaba en Chilpancingo hacfa el año de 1860 , y todavia puede agregársele una mayor antiguiedad tradicional.

Con la mayor amabilidad, la señorita González no obstante encontrarse indispuesta, nos facilitó las melodias de todos los números de canto que, a decir verdad, nos nos produjeron la misma impresión que en el templo cantados por los pastorcitos, y ello se debió a que, deben ser entonados a dos voces, $y$ las que nos trasmitió nuestra informante, son las de la primera voz (el tenor), en tanto que lo que los niños cantaron fué la segunda voz (el soprano), resultando ésta más aguda. La señorita González insistió varias veces, al repetirle lo que dictaba, que estos ejemplos debían de ser entonados con sonidos más altos. 
Los quince ejemplos que forman esta serie fuerón tomados el citado día 13, hasta cerca de las dos de la tarde en que concluyó la entrevista, y dejamos para más adelante la copia del manuscrito.

Ia señorita Fernanda González posee, además de una voz clara $y$ bien timbrada, una magnífica memoria, pues recordó algúb fragmentos faltantes en el manuscrito, asi como algunas otras coplas que sirven parà levantar al Niño Dios en las fiestas dè la Candèlaria.

\section{Cómo es el manuscrito.}

La mañana del sábado 15 , a éso de las diez, nós trasládamó al domicilio de la señorita González, y con su venia procedimós a copiat el texto literario. Está en un cuaderno de unas quince hojas de papel ministro, bastante maltratado por el uso; aparece escrito en máquina, utilizando el color rojo de la cinta, en columnas de versos no siempre bien divididos y sin "separación de escenas. En là parte superior izquierda, de la primera página, 'se lee: "El Ax́gel anuncia el nacimiento". En la partè supèrior derecha GLORIA IN ExcELSIS̀ y aparece el lugar y la fecha en que fué copiado el manuscrito: Chilpancingo, Gro., 28 de noviembre de 1925.

Algunas hojas̀ están sưmamente usadas; dobladàs y hasta remendadas con" otro papel.' Los nombrès de los personajes que hablan quedan consignados al margen y la acción aparece muy ligeramente aćotada. Pára mejor. inteligéncia del desaríollo de estä piezà hémos marcadó cón más claridad los lugáres en que debe intervenir la música; con el número del ejemplo y sè han puesto de relieve aquellos pasajes en que sólo se declaina. Se ha aumentado el número de acotaciones,. especialmente cuando los pastores, por parejas, se acercan al altar, subèn y se retiran, tal como lo vimos ejecutar en el templo. En esta copia del manuscrito se han subrayado algunos madismos o errores de dicción.

Ia labor de copia fué mucho más fácil que el dictado de la música, pues ya teniamos adelantados los textos que la acompañan, de modo que se redujo el trabajo a comprobar la entrada de los cantos y a copiar ordenadamente el resto, desde la anunciación dêl ángel.

Cómo se organiza el grupo de pastores.

Fernandita, como cariñosamente la llaman todos en Chilpancingo, se sirvió, darnos las siguientes informaciones: Todos los jovencitos qué 
forman el grupo lo hacen por devoción y por manda of recida por alguna gracia que han solicitado. Por ejemplo, el niño Pablo Pastor, de seis años, hace algún tiempo estuvo enfermo de pulmonía y of reció al Niño Dios, si se aliviaba, ser pastor hasta que cumpla quince años, que es el término de la edad permitida para pertenecer a este grupo.

Los gastós de vestuario corren por cuenta de los familiares de cada. pastorcito; los báculos son de la propiedád de la señorita González.

Concluido de copiar el manuscrito tuvimos oportunidad de fotografiar tanto a la señóita González como al niño Pablo Pastor, con la indumentaria de mayoral, terminando asf la entrevista.

\section{Consideraciones' sobre la representación.}

E1 hecho de que se cantaran estas adoraciones en el mes de enero, nos hace suponer que estos cantos fueron entonados con motivo de las fiestas de los Santos Reyes, (el día 6) prolongándose la actuación algunos días'más:

Tal como presenciamos esta.adoración, $\sin$ portal, $\sin \mathrm{Niño,} \sin$-Virgen, buey ni mula, se convierte en sólo una repetición devota de lo que se presentó fomalmente là noche de Navidad. Cuidadosamente examinados, tanto el manuscrito como lo que pudímos presenciar, nos hace suponter que se trata de un fragmento de pastorela que en su principio debió tener mayor longitad, con escenas de diablos; seducción de pastores, tentación al ermitaño, lucha entre el ángel y Lucifer, etce; pero quizá por alguna circunstancia especial tuvo que verificarse la representación en el interior del templo únicamente, y pareciendo inconvenientes algunas escenas fueron suprimidas, quedando sólo aquello que no repugnaba con la santidad del lugar. Quedó ređucida entonces esta representación a las sigurientes escenas en que puede ser dividida:

1. Anunciación del ángeł.

2. Levantada dé pastores:

3. Encuentro con el ermitaño.

4. Caminata.

5. Llegada al portal y contempłación.
6. Ofrenda por parejas de pas: tores, mayoral y ermitaño.

7. Levantada de Bartolo.

8. Adoración al Niño Dios.

9. Arrullo.

10. Cánticos.

11. Despedida.

12. Levantada del Niño. 
Aspecto literario.

La versificación que aparece empleada en el manuscrito que estudiamos incluye elementos clásicamente españoles, en metro de villancico exasílabo, coplas octosilabas, estrofas decasilabas y endecastlabas, $y$ un caso de alternancia de estos dos últimos metros. La presencia de versos decasílabos y endecasilabos le resta antigüedad y popularidad, pues hace suponer influencia clásica de los románticos del segundo tercio del siglo XIX ; pero por otra parte, la afluencia de exasilabos y de villancicos retrae los orígenes de esta pieza a los siglos del coloniaje.

Es interesante hacer notar la presencia" de dos "canciones de mayo" dedicadas al Niño Jesús. En ellas, como es sabido, se hace una descripción minuciosa del tostro, o del cuerpo, de la persona a quien se dedica. Ia primera principia: "De oro parecen sus rubios cabellos ..." y son cuatro estrofas exasílabas; en la segunda, cada dos estrofas entonadas por el solista, se intercala el coro: "Aromas se quemen ...", ésta principia: "Son bellísimos tus ojos y rizados son tus cabellos..."

También merece mencionarse el hecho de que durante la adoración de lós pastores, por parejas, cada uno de ellos recita unas décimas espinelas; perfectas en el caso de la pareja del pastor y la pastora del manjar; imperfectas en casos anteriores en que se convierten en novenas o todavía más fragmentarias por la acción del tiempo; también aparecen otras formas de estrofas.

\section{Aspecto musical.}

Los quince ejemplos son muy variados $y$ ofrecen caracteres semejantes a los señalados para la versificación: melodias hispánicas, con ritmos característicos de villancico, especialmente en las "caminatas"; melodías más desarrolladas, según la versificación, propias de las coplas, $y$ aun los versos endecasílabos y decasílabos alternos dan forma a una canción mexicana. (Ejemplo No 10.) Abundan los compases de 6/8; pero no escasean los de $2 / 4,3 / 4$ y $4 / 4$; aunque hay dos ejemplos con compases de $5 / 8$ y $5 / 4$, respectivamente.

El carácter de las melodias tiene justa correspondencia con el acto que se verifica, así los hay entusiastas, alegres, tiernos, contemplativos y hasta con cierto sabor romántico. La canción de mayo: "Son bellísimos 
tus ojos...", a dos partes, contiene mayor espontaneidad lírica; otros ejemplos cambian de compás, logrando mayor variedad rítmica; pero en el que lleva como título: "Pajarillo clarín de la selva...", en su segundo semiperíodo ofrece alternancia de los compaces de $6 / 8$ y $3 / 4$, como en la guajira española y es, probablemente, el ejemplo más característico, quizás influenciado por el primitivo fandango español enraizado, desde la época colonial, en el Estado de Guerrero.

El haber obtenido el texto y la música de esta adoración, constituye para nosotros una verdadera fortuna; pero tenernos noticia de que no es el único ejemplo de este género de representaciones, sino que existen otros muchos, especialmente en la región de Tlalchapa. Esperamos que, en un futuro próximo, nuevas aportaciones de esta índole enriquezcan el acervo del Teatro Popular Religioso del ciclo de Navidad.

EL, ANGEL ANUNCIA EL NACIMIENTO.

Procede de Chilpancingo, Gro. hacia 1860.

Comunicó la señorita Femanda González, de 50 años.

Recolección en el lugar: jueves 13 y sábado 15 de enero de 1949. La sabian: Epifania Castor, abuela de la comunicante y su hija Filomena, esposa de Juan González, padres de la comunicante.

Recolectaron los profesores: Vicente $T$. Mendoza y Virginia $R$. R. de Mendoza.

PERSONAJES

Arcángel Miguel.

Bato y Gila.

Bras y Flora.

Antonio y Armida.

Silvio y la de las uvas.

Monjivel y la de los gemelos.

* Otro pastor y la del majar.

* Sancho (mayoral).

Ermitaño.

Bartolo.

Angel: Llegó el momento, pastores, en que el Mesías prometido

a nuestro suelo ha venido

a prodigarnos su amor.

Ya tenéis entre vosotros

al Dios eterno humanado

a ese Mesías tan deseado,

a ese augusto Redentor. 
E1 romperá las cadenas con que el hombre vive atado y triunfará del pecado que un tiempo Adán cometió.

Id, pastores, a adorar al que Simeón ver deseaba, al que Adonai se llamaba $y$ ahora se llama Jesús.

Ofrecerle ricos dones con amor el más sincero, porque es de Dios el cordero $y$ en fin, vuestros corazones.

Hoy la estrella de Jacob ha aparecido en el cielo. sus rayos bajan al suelo anunciando al Niño Dios.

En un derruido palacio bafiado de eterna luz, encontraréis a Jesús allá en Belén de Juda, en un portal acostado. por querubes adórado. el Hijo de Dios esta.

Triunfando en noche glacial gime de la gloria el Rey, por esto la thula'y el buey' con su vaho le dan calor.

Vertis a la Hija'del Padre, madre del Ómipotente, más radiante y esplendente' que Ios fulgores del sol.

Esa luna sin Menguante; más elevada que el cielo, les trajo al Dios de consteilo, al Verbo eterno de Dios.

Esa fragante azucena llenó de perfume el Padre, Dios Hijo la hizo su Madre, vistiendo (se) de su candor: 
Hoy la veréis de rodillas, reclina ante Dios la frente y llora, suspira y siente, por la orfandad de su Dios.

Ahí esta el patriarca José, el hombre más puro y santo, con los pliegues de sü manto lo arrulla con profunda fe.

Legiones de serafines con cítaras y arpas de oro le cantan todos en coro:

(Cantado) Gloria in excelsis Deo et in terra pax ominibus bone volunitatis laudamuste, benedicinuste, etc. etc.

Bato: Lévantense, compañeros, vamos a adorar al Niño, llevémosle algún presente que aceptarà' con cariño.

Gila: Vamos, 'hermanos pastores," còn régocijo y placer, que afios se me hacen las horas por abrazar a Emmanuel, $y$ agua se me hace la boca por darle besos de miel.

Flora: ¿Por qué estás confuso, Bras? ₹

3ras: Porque no tengo que dar.

Flora: Pués dale tu' corázón.

Bras: Pues qué, ¿me lo he de ariaricar?

Flora: Anda, Bras, y no chancies, sígueme, pues el camino.

Bras : Flórita, dicés muy bien, vamos a adorar al Niño. 
MUSICA Ejemp. 1.

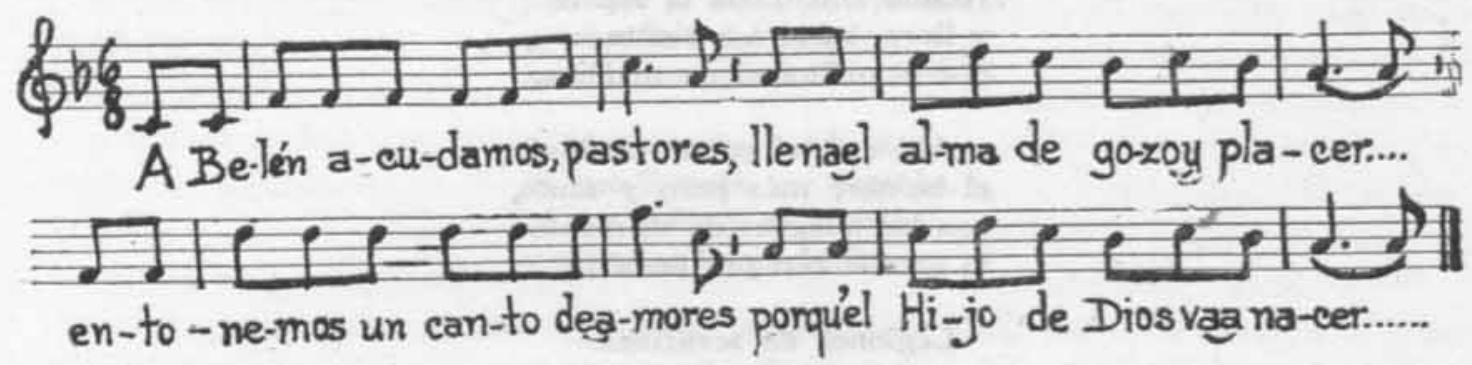

Coro: A Belén acudamos, pastores, llena el alma de gozo y placer, entonemos un canto de amores porque el Hijo de Dios nació ya. (Va a nacer.)

Flora: (Declamado) Ya del mundo se fueron las sombras, el dolor y la fiera amargura, sólo llanto, contento y ventura volverán en la tierra a imperar.

Las cadenas que al mundo oprimían rotas fueron en muchos pedazos y desde hoy han brotado los lazos que en el cielo y la tierra han de estar.

Coro: A Belén acudamos, pastores, etc....

Bras: (Declamado) Las promesas que Adán recibiera por la boca de Dios en un día que él mismo a salvarnos vendría, se ha llegado por fin a cumplir.

Todo el orbe contempla extasiado del Eterno la inmensa clemencia, cuando toma la humana existencia y por todos se ofrece a morir.

Coro: A Belén acudamos, pastores,

Armida: (Declamado) Santo Niño, cordero sin mancha, de la culpa de Adán holocausto, que desdeñas la pompa y el fausto cuando naces en pobre portal. 
Si de humilde nos das el ejemplo

desde niño pobrezas mostrando,

haz, Señor, que te imite llegando

a gozar en tu reino eternal.

Coro: A Belén acudamos, pastores, etc....

(Se supone que llegan a la puerto del templo.)

Sancho: (Declamado) Pastores del sombrerito

yo se los sabré quitar,

Alabado sea el Santísimo

Sacramento del altar.

Hermanos pastores

vamos entonando un canto

para podernos marchar.

Ermitaño: (V'ene caminando y cantando.)

El infierno tiembla, el demonio llora, de ver que ha nacido

el Rey de la Gloria.

Bato: (Declamado) ¿Qué no oyen que alguno canta?

Gila: Se apercibe muy patente, ya le tenemos (aquí) presente y ni la cara levanta.

Ermitaño: Buenas noches, pastores,

Gila: Téngalas usted muy buenas.

¿' ¿Qué gusta usted, señor, * aceptar de nuestra cena?

Ermitaño: Mil gracias por su fineza, sólo vengo a hacer saber que cumplida la promesa hoy acaba de nacer el Mesías en la pobreza. Quiero, pues, tengan a bien que vayamos a adorarle, así como a tributarle nuestro homenaje también. 
Gila: Al momento marcharemos todos para aquel lugar, embarazo no tendremos, vámosle, pues, a adorar. (Inician la marcha.)

\section{Caminata}

MUSICA Ejemp. 2.

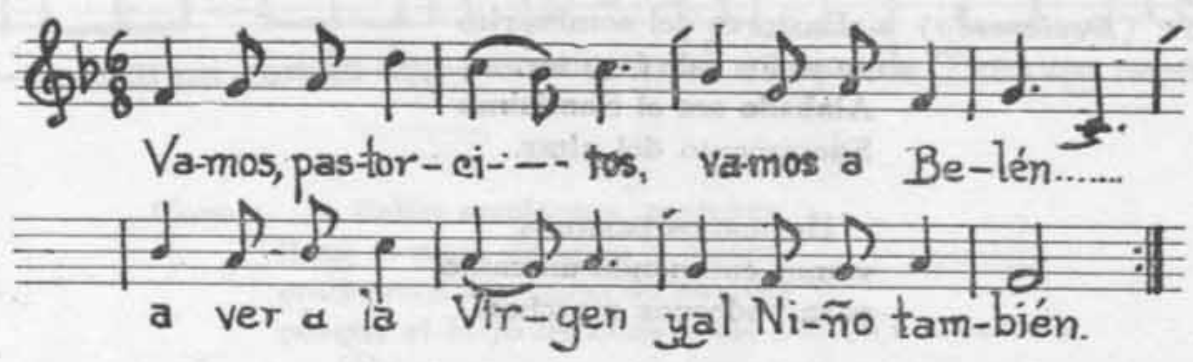

Vamos pastorcitos, / vamos a Belén, a ver a la Virgen / y al Niño también.

Albricias, pastores, / ya el gallo cantó, clarito nos dice / que Cristo nació.

El Angel Miguel / nos vino a avisar, que ha nacido el Niño / dentro de un portal.

iQué gusto tendremos / cuando le tengamos hecho un niño tierno / entre nuestros brazos!

Le diremos: Mi alma, / Señor Soberano, mira qué nos mandas, / pues somos tus criados.

Si algo se te ofrece, / tenemos ganado, puedes disponer / de todo el rebaño. y nuestras personas, / si valieran algo.

A lo que quisieras, / rendidos estamos, felices pastores / aunque despreciados, que del mismo Dios / somos convidados.

Dueño del gallito, / déjanos pasar, que la noche es larga / y tenemos que andar.

Qué lucido está / un cielo estrellado, llenos de delicias / parecen los campos. 
Andemos aprisa, / no nos detengamos que ya del portal / las señas miramos.

IOh portal dichoso, / portal de Belén! donde nació el Niño / para nuestro bien.

Lleguemos corteses, / con los ojos bajos, hinquen las rodillas / cruzando los brazos.

Ya llegamos donde, / este es el portal, pidamos rendidos / licencia de entrar.

Angel: (Declamado) Aquí tenéis el portal dichoso, llegad con adoración a ofrecerle vuestros dones a este divino Señor.

E1 como divino autor a su poder sin segundo ha venido, pues, al mundo, a sacarnos del error.

MUSICA Ejemp. 3(a).

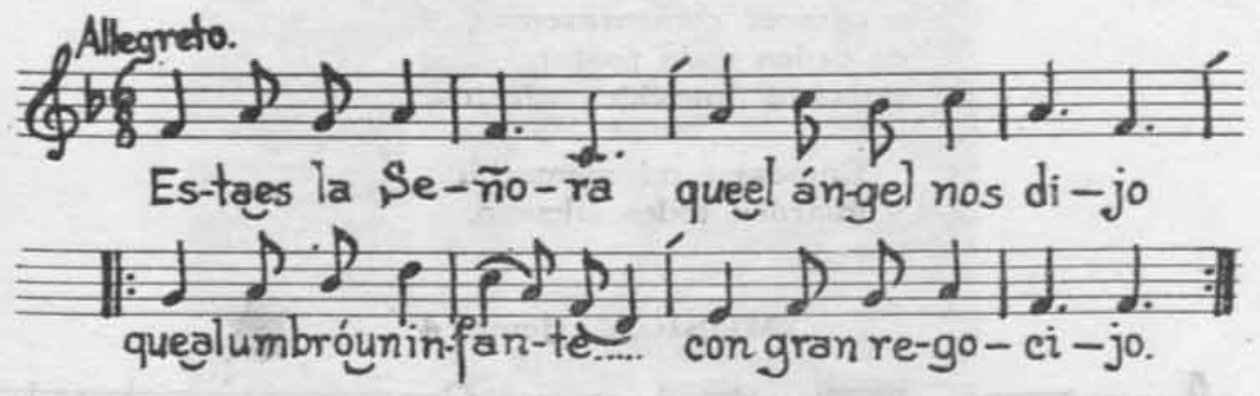

Coro: Esta es la Señora / que el ángel nos dijo, que alumbró un infante / con gran regocijo: pastorcillos, somos, / del cerro bajamos y tremos al Niño / dulces de los ramos.

Los Tres Reyes Magos / vienen del Oriente a darle homenaje / al Omnipotente, del Oriente somos / todos los pastores y traemos al Niño / canastas de flores.

E1 buey con su bau / calienta al Señor, la mula se admira / de su resplandor. 
MUSICA Ejemp. 3(b).

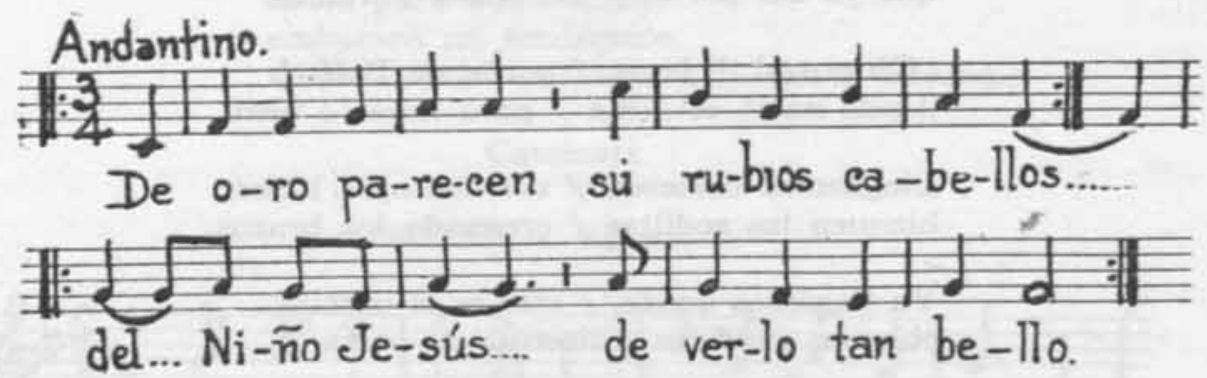

De oro parecen / sus rubios cabellos del Niño Jesús / del verbo tan bello su frente a azucena / trasciende en extremo, como que fué creado / del mismo Supremo.

Sus ojos son dulces / para el Universo, que al portal alumbran / como unos luceros. Sus labios, corales / en tiempo de invierno, que por ellos sale / el poder eterno.

\section{Bato: (Declamado) Aquí tenéis el portal dichoso \\ a ofrecer comenzaremos, en orden cada pastor, nuestros humildes afectos. \\ Empezaré mi memorial y guarden todos silencio.}

\section{MUSICA Ejemp. 4}

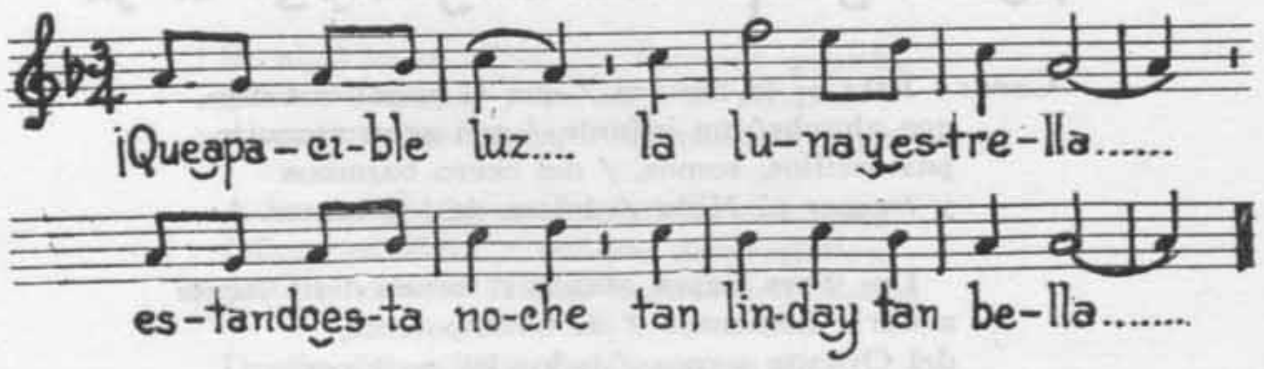

(Ofrenda de dos en dos.)

Qué apacible luz, / la luna y estrella, estando esta noche / $\tan$ linda y tan bella. 
DOI: http://dx.doi.org/10.22201/iie.18703062e.1950.18.501

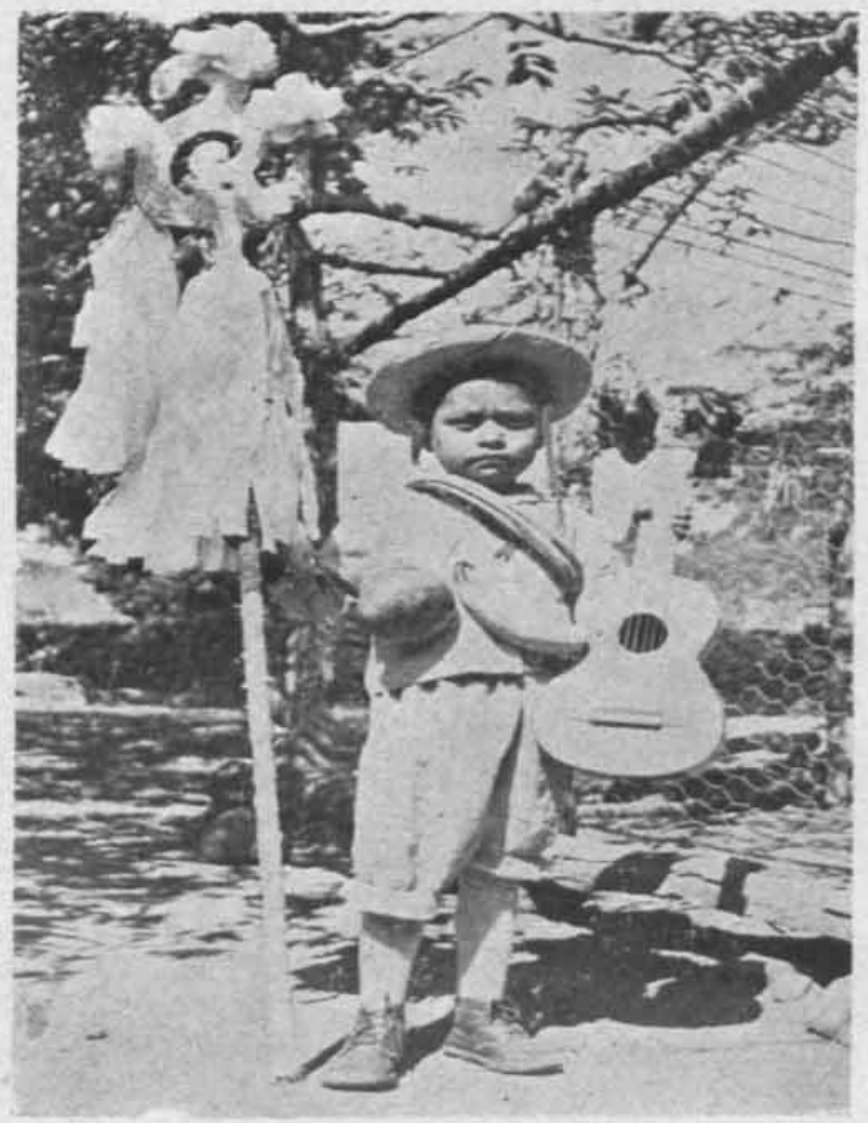

1. Niño Pablo Pastor

on an papel te Sarelue of Mavoral 
DỌI: http://dx.doi.org/10.22201/iie.18703062e.1950.18.501

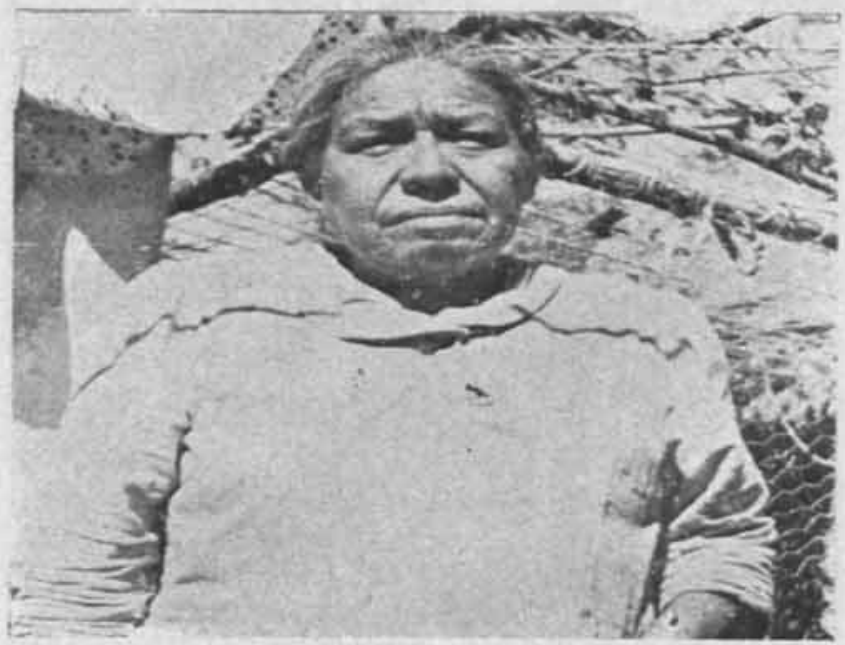

2. Doña Fernanda Gromzález 
DOI: http://dx.doi.org/10.22201/iie.18703062e.1950.18.501

(Bato y Gila se acercan al portal a adorar al Niño.)

Bato: Niño bendito, mi bien amado, de dulces ojos, de blanca tez;

estas mantillitas te he preparado nada más tengo por esta vez.

Pobre es la ofrenda que te dedica cual siervo tuyo este labrador, si algo le falta de bella y rica lo suple mi alma con grande amor.

Gila: Alguna ropa con que del frío cubras tu cuerpo, Dios de bondad, viene encerrada dentro de un lío, a tí la ofrezco con humildad.

Cuando regreses al trono santo de donde bajas para sufrir, llévame al cielo, mi bien, mi encanto, porque contigo quiero vivir.

\section{MUSICA Ejemps. 5 y 6}

Bato: ¿Qué gracia y qué gloria! / iQué gusto y qué bien!

Gila : que el rey de los cielos / ya nació en Belén. (Se retiran.)

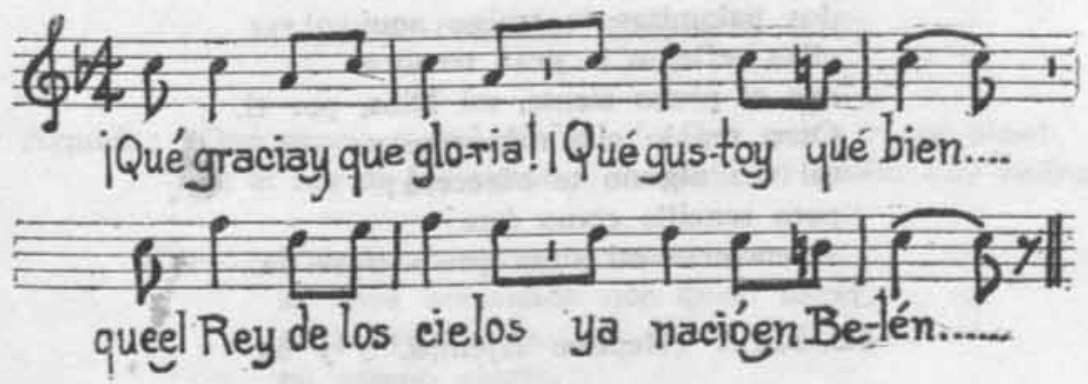

Coro.

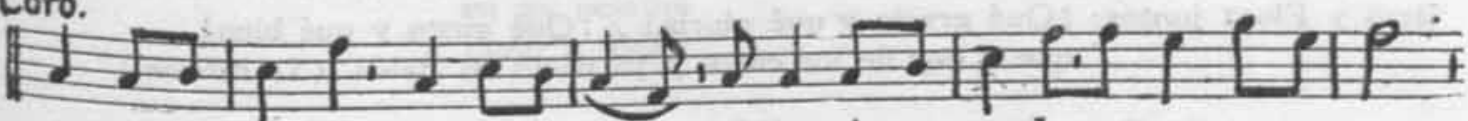

Va-mos,pasto-res, vamos a ver... al Dios huma-nadoque qui-so na-cer

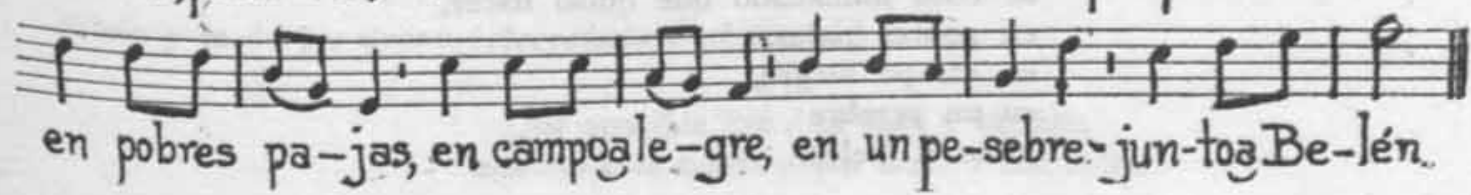


Coro: Vamos, pastores, vamos a ver

al Dios humanado que quiso nacer,

en pobres pajas,

en campo alegre,

en un pesebre junto a Belén.

MUSICA. Ejemp. 4. ¡Qué apacible luz...

(Bras v Flora se acercan ai portal.)

Bras: A padecer has venido

en este mísero mundo

por el amor sin segundo

que a todos nos has tenido;

yo te adoro muy rendido,

divino Niño humanado,

de profetas anunciado

para hacer esta venida.

Penosa será tu vida

para ser el Redentor

iOh gran divino Sefior!

Te traigo estos zapatitos

que a esos lindos piecitos

les entrarán sin dolor.

Flora: Como un emblema de tu dulzura

dos palomitas te traigo aquí,

ellas reflejan la gran ternura

que el pecho siente, mi Dios, por ti.

Otro regalo que más cueste

tal vez alguno te ofrecerá;

pero sencillo como éste

se encierra mi alma que a tí se da.

\section{MUSICA (Repiten Ejemps. 5 y 6)}

Bras y Filora juntos: ¿Qué gracia y qué gloria! / i Qué gusto y qué bien! que el rey de los cielos / ya nació en Belén. (Se retiran.)

Coro: Vamos, pastores, vamos a ver

al Dios humanado que quiso nacer.

en pobres pajas,

en campo alegre,

en un pesebre

junto a Belén. 


\section{MUSICA (Repite Ejemp. 4)}

Antonio y Armida: (Se acercan al portal.)

¡Qué apacible luz, / la luna y estrella

estando esta noche / $\tan$ linda y tan bella!

Antonia: (Declamado) De mi rebaño lo más florida el corderito de albo vellón, pongo a tus plantas, mi bien, rendido, pidiendo aceptes mi humilde don. Joyas muy ricas tener quisiera de gran belleza $y$ de gran valor asi, aunque poco me pareciera, para of recerlas al Salvador.

Armida: (Declamado)
A padecer has venido

a este mísero mundo por el amor sin segundo que a todos nos has tenido; así ahora te pido acoge a esta pastorcita quien trae una camisita para tu Niño sagrado; recíbela con agrado Virgen gloriosa $y$ bendita.

\section{MUSICA (Repiten Ejemps. 5 y 6)}

Antón y Armida: ¡Qué gracia y qué gloria! / ¿Qué gusto y qué bien! qute el rey de los cielos / ya nació en Belén. (Se retiran.)

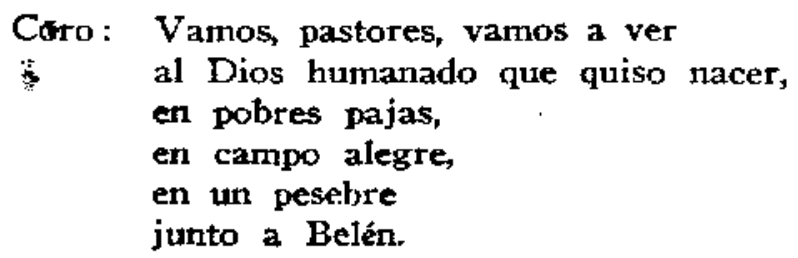

\section{MUSICA (Repite Ejemp. 4)}

Silvio y la de las uvas: (Acercándose al portal.)

Qué apacible luz / la luna y estrella estando esta noche / tan linda y tan bella. 
Silvio: (Declamado) A tus pies soberana Virgen

pongo mis cinco sentidos

por ser tan esclarecidos

vuestros candores ufanos.

Aquí está mi amor cebrero (sincero)

ya sabes que te venero

como humilde pastorcito

para el divino cordero

recibe este corderito.

Ella: Uvas frescas te corté

en el camino que habia;

cómelas, pues, con María

$y$ ese divino Jesús. (sic) (José?)

Cosa mejor no encontré

que traerte, Niño querido,

sólo estas blancas palomitas

que dormidas $y$ solitas

en stu nido las hallé.

MUSICA (Repiten Ejemps. 5 y 6 )

Silvio y su pareja: ¡Qué gracia y qué gloria! / i Qué gusto y qué bien! que el rey de los cielos / ya nació en Belén. (Se retiran.)

Coro: Vamos, pastores, vamos a ver

al Dios humanado que quiso nacer,

en pobres pajas,

en campo alegre,

en un pesebre

junto a Belén.

MUSICA (Repite Ejemp. 4)

Monjivel y la de los gemelos: (Acercándose al portal.)

Qué apacible luz, / la Iuna y estrella

estando esta noche / tan linda $y$ tan bella.

Monjivel: (Declamado) Soy de Monjivel, (que) monjivelo,

que entre lóbregas montañas,

entre espinas y marañas

anduve mirando al suelo,

alcé los ojos al cielo

y luego a (mi) Dios aclamé,

rompió el alba con su luz

y para el Niño Jesús

este fajero the halle. 
Ella: Con humilde acatamiento yo me acerco a este lugar con el fin de venerar a este singular portento. t Oh singular pensamiento del Eterno que te envió! Hoy de agradecida yo te traigo estos gemelitos que una madre los crió.

\section{MUSICA (Repiten Ejemps. 5 y 6)}

Los dos: ¡Qué gracia y qué gloria! / ¡Qué gusto y qué bien! que el rey de los cielos / ya nació en Belén. (Se retiran.)

Coro: Vamos, pastores, vamos a ver al Dios humanado que quiso nacer, en pobres pajas, en campo alegre, en un pesebre junto a Belén.

MUSICA (Repite Ejemp. 4)

Un pastor y la del majar: (Acercóndose al portal.)

Qué apacible luz, / la luna y estrella estando esta noche / tan linda y tan bella.

El pastor: Yo, Santo Niño, quisiera que ya pudieras andar y fuésemos a jugar * por aquella verde pradera; * mas ya que de esta manera salen fallidas mis ganas, te traigo estas avellanas y algunos juguetitos. Jućgalos, Niño chiquito, mañana por la mañana.

La del majar: Yo como sé que careces de dientes para masticar te traigo un rico manjar tal como tú lo mereces. Yo quisiera varias veces repetir este presente; 
mas temo que de imprudente se me vaya a mí a tener, empiézalo hoy a comer, Niño Dios Omnipotente.

\section{MUSICA (Repiten Ejemps. 5 y 6 )}

Los dos: iQué gracia y qué gloria! / iQué gusto y qué bien! Qué el rey de los cielos / ya nació en Belén. (Se retiran.)

Coro: Vamos, pastores, vamos a ver

al Dios humanado que quiso nacer,

en pobres pajas,

en campo alegre,

en un pesebre

junto a Belén.

MUSICA (Repite Ejemp, 4 con la letra de abajo)

Sancho: (Se acerca al portal tocando $y$ bailando.)

Tocando y bailando / voy para el portal

a darle las gracias / al rey celestial.

MUSICA (Repiten Ejemps. 5 y 6 )

Ya Sancho se va / a ver su ganado

que de humilde oveja / vendrá el ermitaño. (Se retira.)

Coro: Vamos, pastores, vamos a ver

al Dios humanado que quiso nacer,

en pobres pajas,

en campo alegre,

en un pesebre

junto a Belén.

\section{MUSICA (Ejemplo 7)}
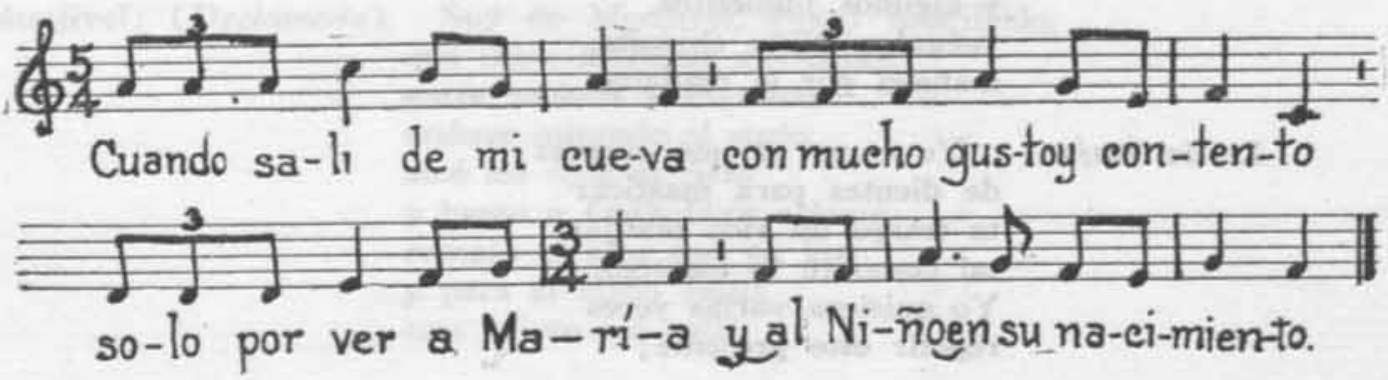
Ermitaño: (Se acerca al portal.)

Cuando salí de mi cueva con mucho gusto y contento sólo por ver a María y al Niño en su nacimiento.

(Declamado) Peregrino soy, gran Niño, que he venido de mi cueva para venir a adorar al Niño Dios humanado. Memorias ruines y pobres de los placeres mundanos sólo te ofrezco mi cruz y fervientes oraciones.

MUSICA (Repiten Ejemps. 5 y 6 )

Adios madre mía, / adios, madre, adios; que el Bato y la Gila / canten arrorró. (Se retiran.)

Coro: Vamos, pastores, vamos a ver

al Dios humanado que quiso nacer, en pobres pajas, en campo alegre, en un pesebre junto a Belén.

\section{MUSICA (Ejemplo 8)}

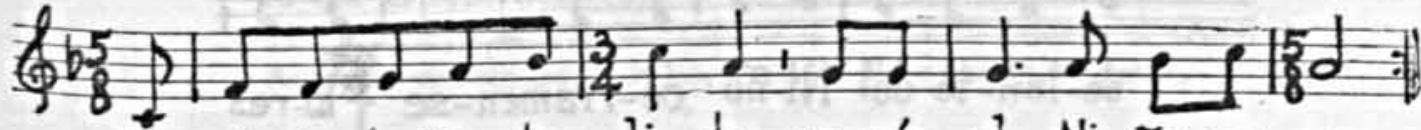

- Le-ván-ta-te. Bar-to-li-to, ve-rás al Ni-ño na-cer.

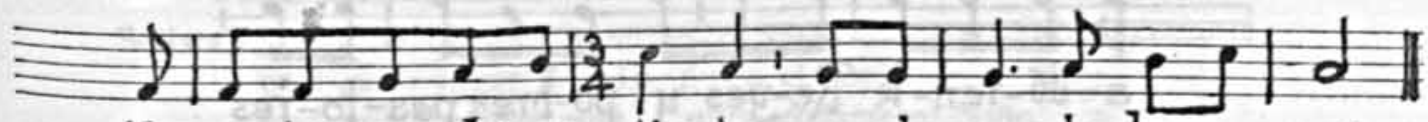

- Ahoraes-tá muy chiqui - ti-to, cuando grande lo ve - ré.

Levantada de Bartolo: (Todos lo rodean.)

Gila: Levántate, Bartolito, / verás al Niño nacer.

Bartolo: Ahora está muy chiquito, / cuando grande lo veré.

Bato: Levántate, Bartolito, / que la aurora va a rayar. 
DOI: http://dx.doi.org/10.22201/iie.18703062e.1950.18.501

Bartolo: Quitate de aquí, Batito, / y déjame descansar.

Flora: En Belén está un bautizo, / Bartolo, vamos allá.

Bartolo: Si me quieren dar mi bolo, / que me lo traigan acá.

Bras: Abandona, Bartolito, / tu pereza sin igual. ,

Bartolo: Ya no me estés molestando, / déjame dormir y roncar.

Gila, Bato y el Angel: Un Angel es (el) que se empeña / en venirte a levantar.

Bartolo: Abandonaré mi sueño, / vamos a Dios a adorar, si sigo con mi flojera / es preciso confesar

que al instante que me muera / Satanás me ha de llevar.

(Se levanta.)

MUSICA (Ejemplo 9)

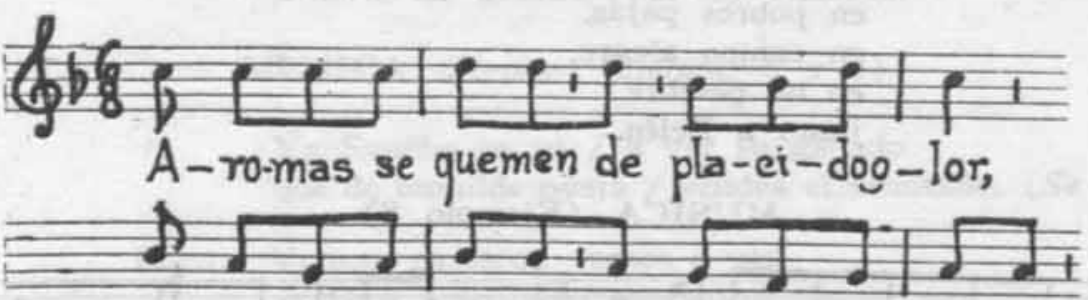

de-lan-te del Ni-ño de-rrámen-se flo-res

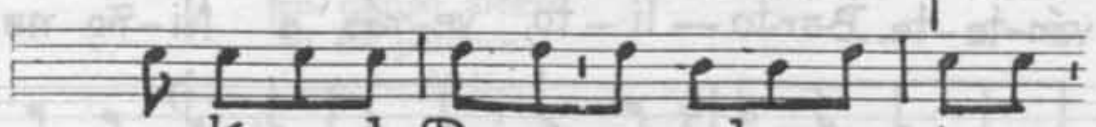

a-dó-ren-le Re-yes y po-bres pas-to-res

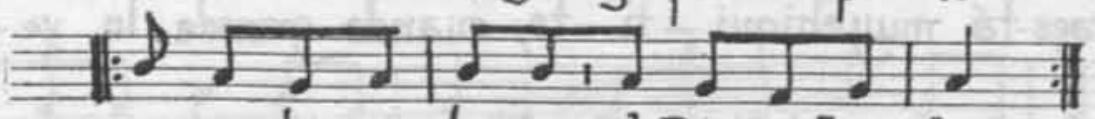

y can-tos en -to-nen al Dios sal-va-dor.

Coro: Aromas se quemen de plácido olor delante del Niño derrámense flores, adórenle reyes y pobres pastores y cantos entonen al Dios Salvador. (bis.) 

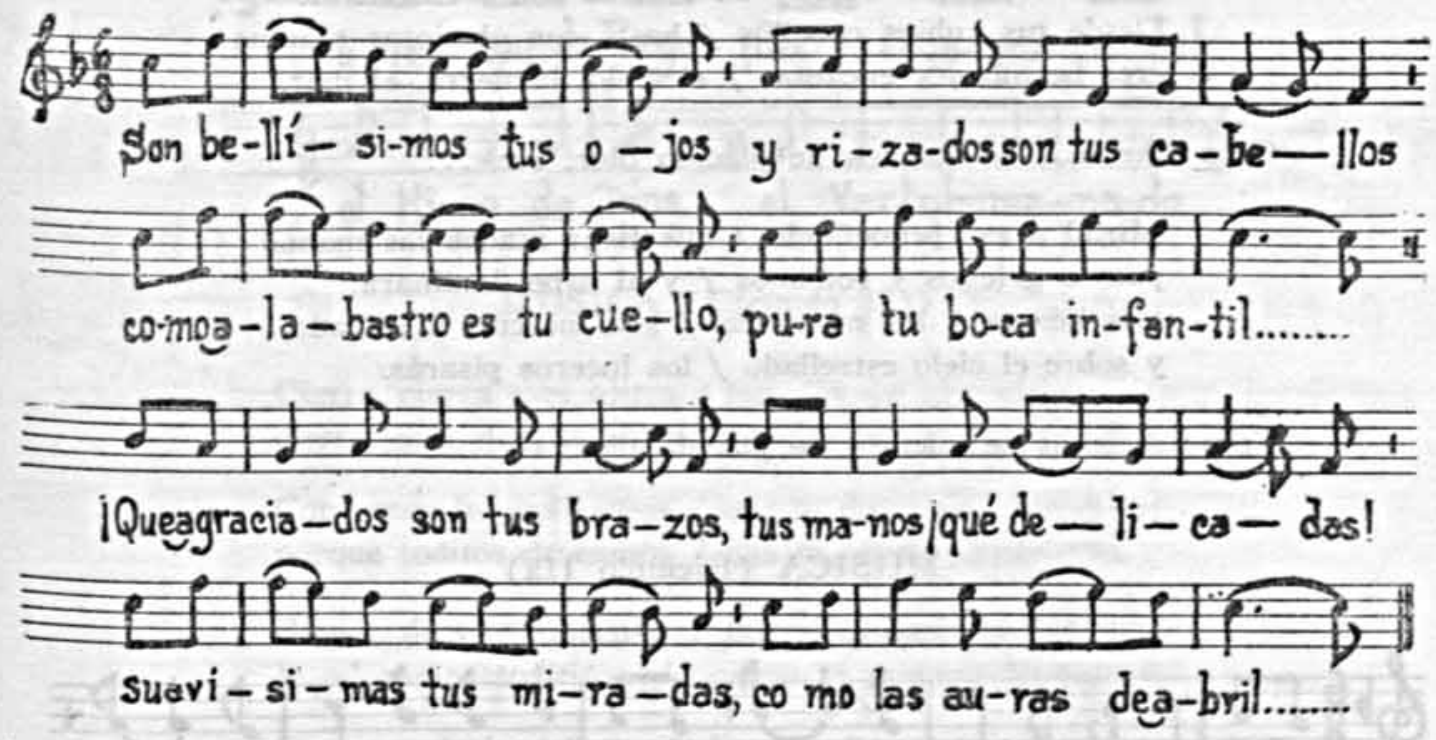

Solista: Son bellísimos tus ojos / y rizados son tus cabellos, como alabastro es tu cuello, / pura tu boca infantil.

Qué agraciados son tus brazos, / tus manos, qué delicadas, suavísimas tus miradas / como las auras de abril.

Coro: Aromas se quemen de plácido olor, etc. ...

Solista: Acostado sobre hierbas / estás ceñido de fajas, tú que el orbe desencajas / en las horas de furor. ¿En dónde apagaste el rayo? / ¿en dónde dejaste el trueno? Amor te acostó en el heno, / te ha desarmado el amor.

Coro: Aromas se quemen de plácido olor, etc. ...

Solista: Juega en tu boca preciosa / cierta inocente sonrisa, cual suele jugar la brisa / con el botón de la flor; mas una lágrima pura / mira rodársete, Niño, ¿es el llanto del cariño? / ¿es el llanto del dolor?

Coro: Aromas se quemen de plácido olor, etc. ...

Solista: Tu linda y cándida madre / te da besos y te mira, te acaricia y suspira / pensando en Getsemaní; abrázate conmovida / y llora y vuelve a los besos al contemplar los excesos / de tu pueblo contra tí.

Coro: Aromas se quemen de plácido olor, etc. ... 
Solista: Si los ángles volando / pasan de estrella en estrella una criatura tan bella / no han de poder encontrar. Desde tus rubios cabellos / hasta tus gloriosas plantas eres hermoso y encantas / el cielo, la tierra, el mar.

Coro: Aromas se quemen de plácido olor, etc. ...

Mirad a ese pequeñuelo / que tiene atadas las manos pues a griegos y romanos / y al orbe dominará.

Los héroes y los monarcas / son insectos a tu lado, y sobre el cielo estrellado / los luceros pisarás.

Coro: Aromas se quemen de plácido olor, etc. ...

MUSICA (Ejemplo 11a)

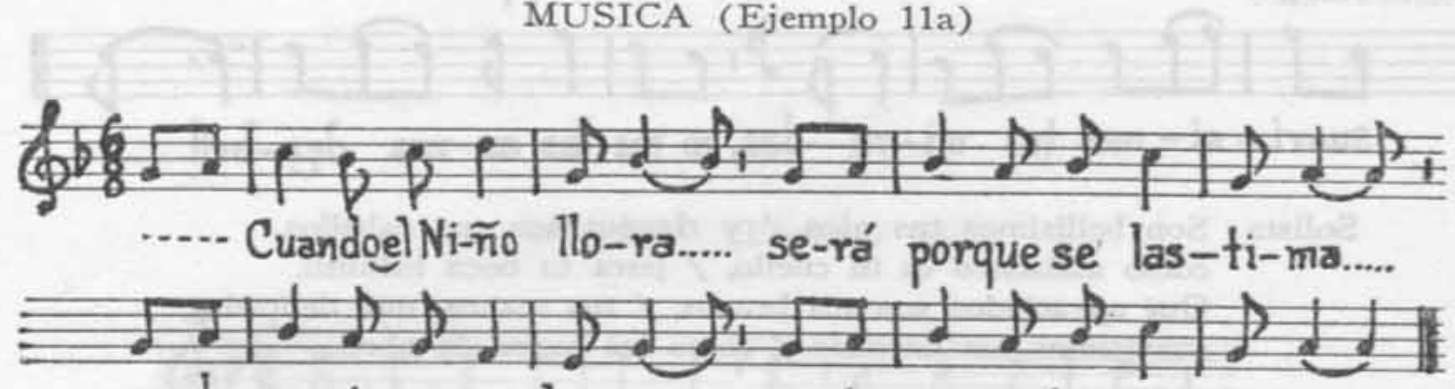
con las es-pi-nas y a-bro-jos.... que la pa-ja tie-neen-ci-ma...

Dormida o arrullo:

Cuando el Niño llora / será porque se lastima con las espinas y abrojos / que la paja tiene encima.

Duérmete, divino Niño, / duérmete, porque hace frío; duérmete, pedazo de oro; / duérmete, regalo mío.

A la ru, divino Niño, / a la ru, mi gran Señor; pues naciste de María / dando al mundo resplandor.

A la ru, divino Niño, / a la ru, Niño sagrado; duérmete, pedazo de oro; / duérmete, rey ensalzado.

MUSICA (Ejemplo 11b)

Eres rey de reyes $i$ oh Niño agraciado! el Hijo de Dios, el Verbo humanado. 


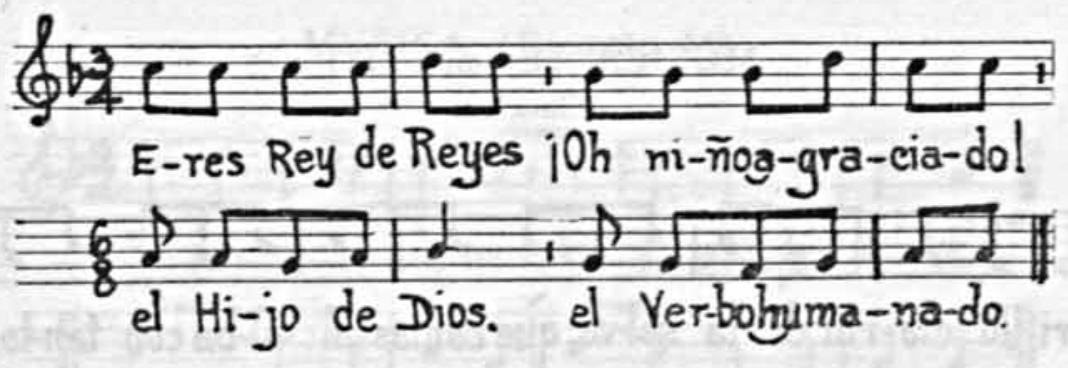

\section{MUSICA (Ejemplo 11a)}

Cierra, cierra esos ojitos / bajados del alto cielo; cierra esos dos luceritos, / te pedimos con anhelo.

Con amor te suplicamos / que te duermas, chiquitito; porque toditos deseamos / que te quedes dormidito.

Somos doce pastorcitos / que adoramos al Señor, lo adoramos todititos, / porque es nuestro Redentor.

Pastores de la cabaña / vienen a buscar ventura, unos a adorar al Niño / y otros a mecer su cuna.

Ya el Niño quedó dormido, / dormido el rey consagrado; entreguémoslo a María, / que lo reciba en sus brazos.

\section{(Devuelven el Niño a la Virgen.)}

\section{MUSICA (Ejemplo 12)}

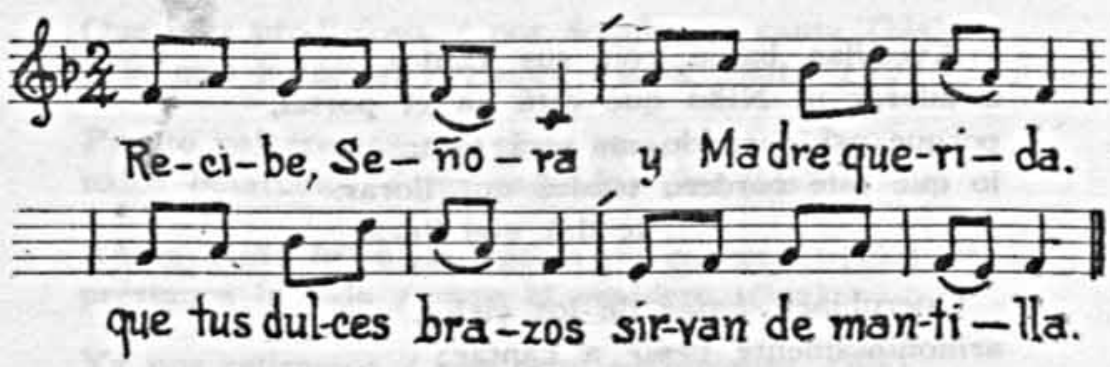

Coro: Recibe, Señora y madre querida, que tus dulces brazos sirvan de mantillas.

Niño, aquí te acuesto en este lugar, hasta el día de Reyes te he de levantar. 


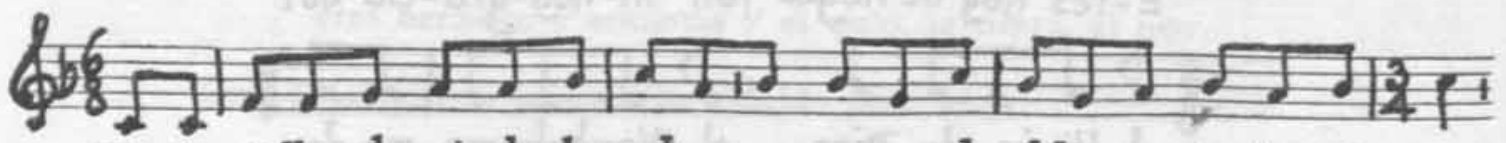

Pa-ja-ri-llo cla-rín de la sel-va, que eantas al al-bacon tanto pri-mor

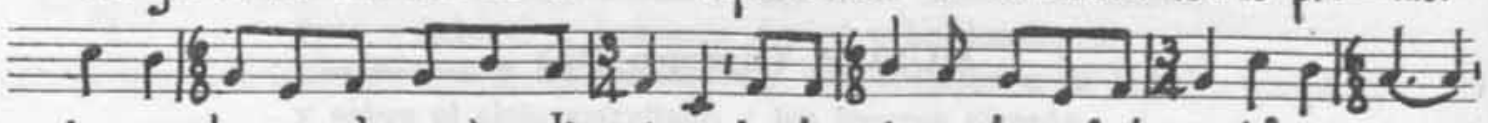
siencon-traras al pastor di-vi-no le di-rás quetriunfe de nuestropre-sor.....

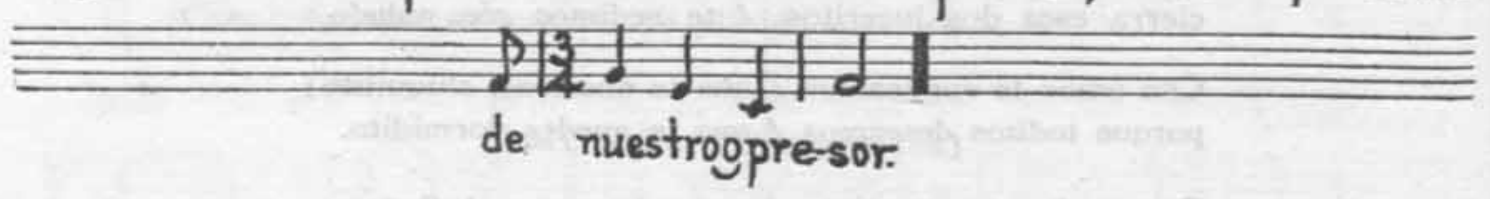

Pajarillo, clarín de la selva que cantas al alba con tanto primor, si encontrares al pastor divino le dirás que triunfe de nuestro opresor.

de nuestro opresor.

El demonio con sus alaridos a toda la tierra la hace temblar, porque sabe que el rey ha nacido quien a su cabeza ha de quebrantar. ha de quebrantar.

Avecillas bajen con sus cantos a adorar al Niño que está en el portal, porque así dormido no será tanto lo que este cordero tendrá que llorar. tendrá que llorar,

Querubines, bajar de los cielos, armoniosamente venir a cantar; con los santos al enviado hermoso que al género humano viene a rescatar. viene a rescatar. 
MUSICA (Ejemplo 14)

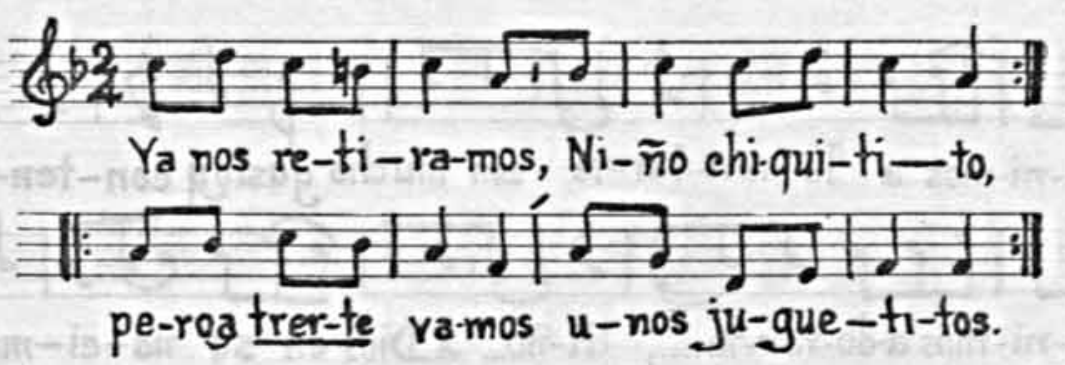

DESPEDIDA.

Coro: Ya nos retiramos / Niño chiquitito, (bis) pero a traerte vamos / unos juguetitos. (bis)

Soberana Virgen, / sagrada y bendita; (bis) al Niño le traigo / estas mantillitas. (bis)

Sagrada María, / nosotros nos vamos (bis) en el corazón / todos te llevamos. (bis)

Patriarca José, / por el monte vamos (bis) en el corazón / todos te llevamos. (bis)

Danos, Niño hermoso, / una fiel mirada (bis) que seamos dichosos / en la retirada. (bis)

(Por doquier se canta / (cuenta) que eres prodigioso) (bis)

Que eres prodigioso, / por doquier se canta (bis) y la más hermosa, / Santa, Santa, Santa. (bis)

Pronto volveremos / a verte otra vez, (bis) todos besaremos / tus sagrados pies.(bis)

Adios, Niño hermoso, /adios mi consuelo, (bis) préstanos la vida / para el venidero. (bis)

Ya nos retiramos / con gran sentimiento, (bis) pero te llevamos / en el pensamiento. (bis)

Adios, Niño hermoso, / adios, mi querido; (bis) dirígenos, Padre, / por un buen camino. (bis)

Tu dulce mirada / nos lleve triunfando (bis) a tu eterna gloria / a estarte adorando. (bis) 


\section{MUSICA (Ejemplo 15)}

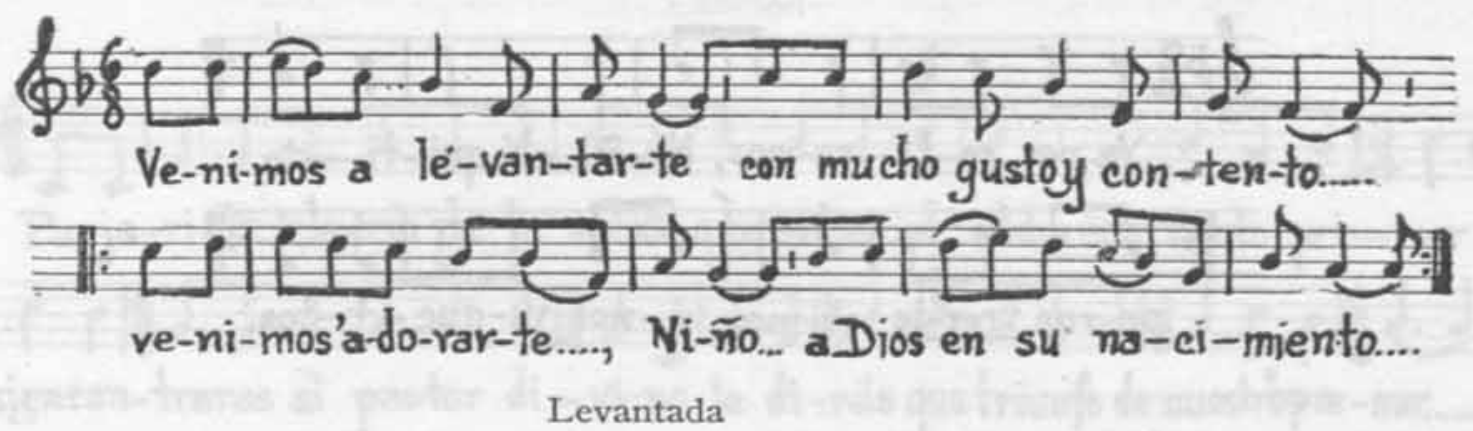

Venimos a levantarte / con mucho gusto y contento; venimos, Niño a adorarte, / a Dios en su nacimiento.

Y los pájaros le canten / y los campos reverdecen; de ver que el Dios ha nacido / hasta los campos florecen. 